\title{
Application of GIS and crop growth models in estimating water productivity
}

\author{
Amor V.M. Ines ${ }^{\mathrm{a}, *}$, Ashim Das Gupta ${ }^{\mathrm{a}, 1}$, Rainer Loof ${ }^{\mathrm{a}, \mathrm{b}, 2}$ \\ ${ }^{\mathrm{a}}$ Water Engineering and Management, School of Civil Engineering, Asian Institute of Technology, \\ P.O. Box 4, Klong Luang 12120, Pathumthani, Thailand \\ ${ }^{\mathrm{b}}$ Office of Accelerated Rural Development, 3/12 U-Thong Nok Road, Sunantna Palace, \\ Dusit, Bangkok 10300, Thailand
}

Accepted 3 September 2001

\begin{abstract}
Tighter competition in water use is projected in the future. As water demand increases, water related problems could happen along the way. Accordingly, issues on water availability and use could be crucial to study to search for ways and means on how to cope up with the present trend. Sound water management practices could play a key role to the solution of problems relating to water availability and use. Water use in agriculture is considered the highest among other water users because of the water intensive processes involved in it. Aside from the crop water requirements, water loss, which are not beneficial to crop processes can add a huge volume to the total water usage in agriculture. Base from this argument, there could be greater possibility to save water from agriculture, which can be used for other purposes thereafter. To explore this option, analysis at the crop level could be beneficial. However, the issue of scaling should be also considered because the knowledge on the field scale could not be generally true in the basin scale. The objective of the study was to apply crop growth simulation models coupled with geographic information system (GIS) to analyze water productivity, which is an indicator of water use efficiency, at the basin scale.

The methodology was applied to Laoag River Basin in Ilocos Norte, Philippines to study water productivity in spatial and temporal dimensions. Three crops were considered in the analysis: rice, maize and peanut. Simulations were done for both existing and potential agricultural areas. The potential productions of the selected crops from October 1996-September 1997 were used as bases in determining water productivity for the three cropping seasons (CS) being considered in the study. Water-limited productions were simulated for each of the crops, for each of the CS in the basin. Moreover, a marginal productivity analysis was done to determine the potential of water for crop

\footnotetext{
* Corresponding author. Tel: +66-2-524-5795; fax: +66-2-524-6425.

E-mail addresses: iwc998357@ait.ac.th (A.V.M. Ines), adg@ait.ac.th (A.D. Gupta), loof@altavista.com (R. Loof).

${ }^{1}$ Tel: +66-2-524-5556; fax: +66-2-524-6425.

${ }^{2}$ Tel: +66-2-524-5560/243-0029; fax: +66-2-524-6425/243-0029.
} 
production in the basin. Subsequently, the significance of irrigation was emphasized in the analysis when availability of water, and the combination of water and nitrogen $(\mathrm{N})$ are limiting, respectively. The results showed that the spatio-temporal analysis of water productivity could provide substantial information for water saving opportunities and, hence, strategies in irrigated agriculture. (C) 2002 Elsevier Science B.V. All rights reserved.

Keywords: Water productivity; Spatio-temporal analysis; GIS; Crop models; Irrigation

\section{Introduction}

Water is finite, thus, a limited resource. As such, it should be managed and used accordingly. According to recent studies, there appears to be an increasing competition in water use as the demand of water increases with the growing population (Molden, 1997; Seckler et al., 1998). Therefore, the concept of a rational approach in water utilization is worth considering. When issues like water supply and demand are put into terms, usually balancing the two is the ultimate goal. One approach to check if the supply is adequate to meet the demand is to account the respective components in the water balance. By doing so, it provides an opportunity to search for possible ways to save water from an application and allocate it with the other. This is termed water saving (Seckler, 1996). If the idea of water saving exists in domestic or industrial water use, this could also be applicable in agriculture. In recent literature (e.g. Droogers et al., 2000), water saving issue in irrigated agriculture has been given importance. The approach was implemented by defining the components of the water balance through simulation models and analyzing opportunities of water saving.

Water use in agriculture has been rated the highest among other water users (Seckler, 1996). Hence, it could give vital information to the development of improved water use. A promising approach is to determine the potential of water considering its interrelationships with the soil, plant and the atmosphere. Water use analysis based on the productivity of water consumed instead of on yield, has been advocated as a promising indicator to analyze water use (Molden, 1997). This overcomes the weakness of other indicators such as water use efficiency where the mass of product produced is not expressed explicitly. Water productivity then is a good index in analyzing the potential of water in a point in space.

Molden (1997) defined three levels of water productivity: the water productivity relative to net inflow, depletion and process depletion, respectively. Net inflow corresponds to the difference of the gross inflow and storage in the water balance; depletion is the evapotranspiration and process depletion, the transpiration only. Water productivity in this definition is taken as the ratio of the yield with any of the three components above. In addition to these levels, the water productivity relative to the depth of irrigation required, can directly measure the significance of water in space and time. This level can be only evaluated if one knows the potential and rainfed productions of the area. In this paper, this water productivity level is evaluated. This level of water productivity is different from the water productivity relative to irrigation as evaluated by Droogers and Kite (2001). 
The potential and rainfed productions can be determined through field experiments. One or two experiments can be practical; however, for multiple seasons and regarding geographic locations, it may be difficult. To overcome this difficulty, simulation models could be used to bridge the gap in time. Through models, one can study processes taking place in the soil-plant-atmosphere continuum and perform scenario testing. This approach allows revisiting the past, simulating the present and predicting the future, thus, made it flexible in all situations. With an improved capability to predict environmental parameters, proper management intervention could be done to minimize risk in the future. The water productivity levels can be easily evaluated using simulation models.

Another issue is the spatial and temporal dimension of water productivity. A spatiotemporal analysis could broaden the role of models in exploring improved water use in agriculture (Ines, 1999). The use of geographic information system (GIS) and crop models allow more efficient analysis because the temporal and spatial dimensions could be studied at once.

The objective of this paper is to demonstrate the potential of crop growth models using GIS data in the spatio-temporal analysis of water productivity. It is envisaged that the result of the analysis will provide additional knowledge on issues of water saving strategies in agriculture.

\section{Materials and methods}

\subsection{Description of the study area}

The Laoag River Basin is located in Ilocos Norte, Philippines in the northern part of Luzon. It is geographically situated between latitudes $17^{\circ} 45^{\prime}$ and $18^{\circ} 15^{\prime}$, and between longitudes $120^{\circ} 30^{\prime}$ and $121^{\circ} 00^{\prime}$. The river system drains an approximate area of $1331 \mathrm{~km}^{2}$ into the South China Sea at Laoag City (Fig. 1).

The climate in the basin is characterized by two seasons, the wet, during May-October and dry season, during November-April. Average annual rainfall is estimated to be $2000 \mathrm{~mm}$ at Laoag City of which $97 \%$ is concentrated in the wet season. An average of five typhoons every year hit or came close to Northern Luzon bringing heavy rainfalls on the basin (JICA, 1996).

The water in the river is mainly used for irrigation purposes. Agricultural lands cover about 33,572 hectares or approximately $25 \%$ of the total land area. Irrigated agriculture comprises $36 \%$ of the total agricultural areas, majority of the irrigation systems are runoff the river type (a system where a small dam structure is constructed across the river to divert the water to the command area); the rests are lowland and upland rainfed agriculture (JICA, 1996). The irrigated areas are only identified according to the irrigation service areas covered by the National Irrigation Administration (NIA). Shallow wells are also used for irrigation within the irrigated and non-irrigated areas (outside the services of the surface water systems).

More than $50 \%$ of the land area is mountainous and the soils in the plains are predominantly clayey to silty clay loam. Soil depths are range from very shallow to deep, with the majority of the soil's fertility vary from moderate to very high; mountain soils 


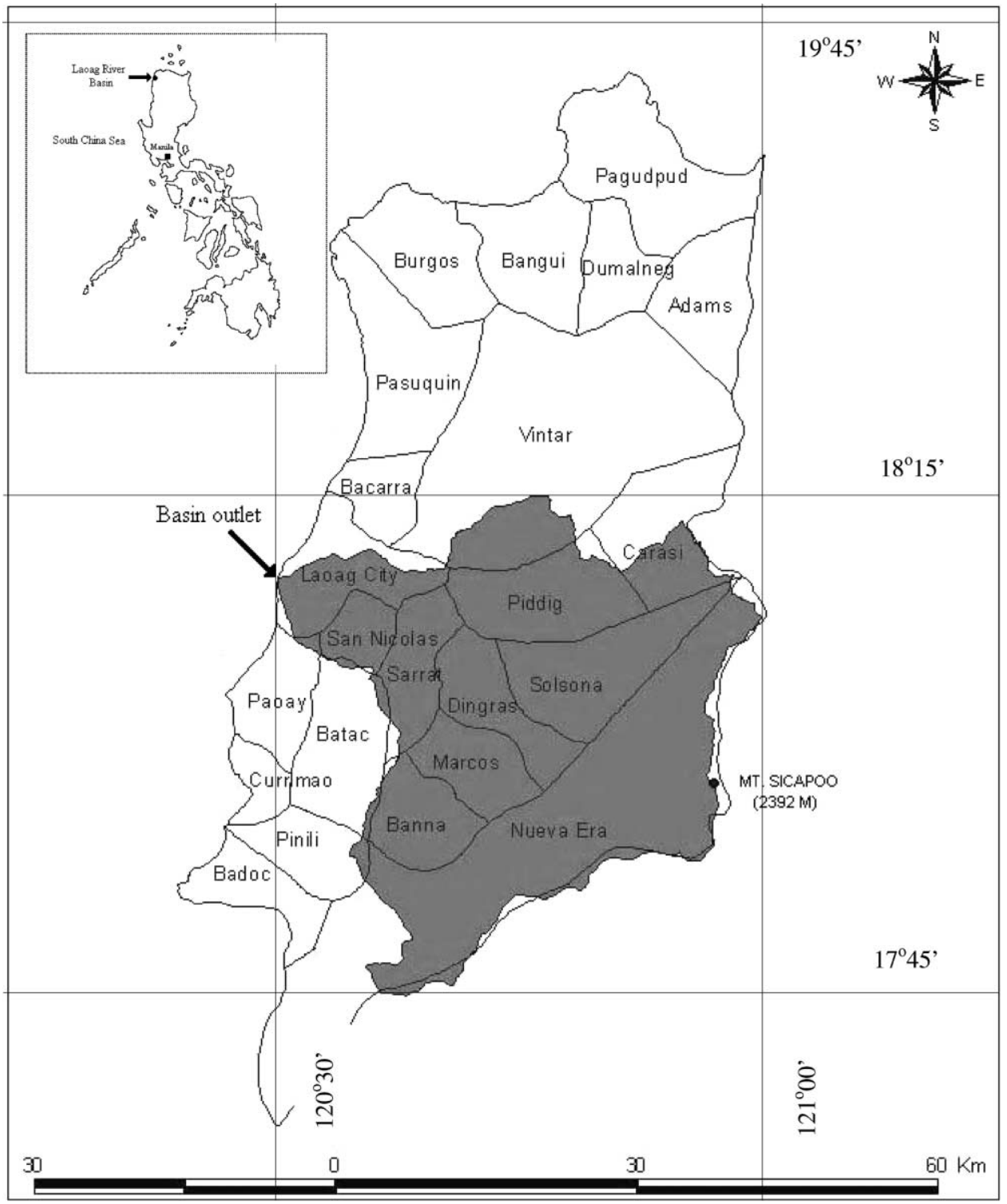

Fig. 1. Location of the Laoag River Basin in Ilocos Norte, Philippines.

are fertile because of their high organic matter contents. Erosion is not a severe problem in the plains but could be noticed in moderately sloped areas in the basin. A majority of the land area is not prone to severe flooding but there are times of the year that floods could devastate the agricultural areas situated in the flood plains (BSWM, 1990).

The major crop in the basin is rice, sometimes grown three times a year in the irrigated areas and usually once in the rainfed areas. Rice is mostly followed by other major cash 
crops such as garlic, onion, mungbean, peanut, maize, watermelon, vegetables, cotton and tobacco for the rest of the year.

\subsection{Spatial analysis}

This paper presents a planning problem where the potential of water for crop production in the river basin was examined not just on the present agricultural areas but also to areas that could be converted for agricultural production. With this in mind, a suitability analysis for the selected crops, i.e. rice (Oryza sativa), maize (Zea mayz) and peanut (Arachis hypogea), was conducted using a GIS. The criteria in the analysis were generally classified as physical and ecological attributes. The physical attribute had a weight of 0.45 while ecological attribute was given 0.55 . Under physical attribute were soil type, soil depth and slope, while ecological attribute were agro-climatic, erosion, soil fertility and flood hazards. Each land characteristic between the two criteria was given also a corresponding weight, but within the criterion, summation of weights should be 1; the weights are important to give distinctions among the land characteristics. The determination of the weights, however, was only based on the researcher's point of view on the importance of the land characteristic to the crop being studied. There could be more scientific way to establish these weights. An additive scoring system was adopted to differentiate the land units in the basin. Each component of the two criteria could score from 0 to 10 based from the environmental requirements of the selected crops (Table 1), then multiplied by their corresponding weights. The total score of the land unit under each criterion were multiplied by the overall weights of the two (i.e. 0.45 and 0.55). An overlay of the physical and ecological attribute map resulted to a map of potential land units. The available regions were derived from this map by deducting the unavailable areas (e.g. built-up areas, sand dunes, forest, etc.) and the threshold levels from the total

Table 1

Environmental requirements of the selected crops (after PCARRD, 1986 ${ }^{\mathrm{a}}$; BSWM, 1990 ${ }^{\mathrm{b}}$ )

\begin{tabular}{|c|c|c|c|c|c|c|c|c|c|}
\hline Crops & $\begin{array}{l}\text { Slope } \\
(\%)\end{array}$ & $\begin{array}{l}\text { Depth } \\
(\mathrm{cm})\end{array}$ & Texture & Drainage & $\mathrm{pH}$ & Fertility & $\begin{array}{l}\text { Flood } \\
\text { tolerance }\end{array}$ & $\begin{array}{l}\text { Erosion } \\
\text { hazard }\end{array}$ & $\begin{array}{l}\text { Water } \\
(\mathrm{mm})\end{array}$ \\
\hline & \multicolumn{9}{|c|}{ Optimum value } \\
\hline Rice & $0-3$ & $\geq 50$ & $s l-c^{d}$ & $\mathrm{p}^{\mathrm{e}}$ & $5.0-7.5$ & Medium $(>\mathrm{N})$ & High & None & $800-1000$ \\
\hline Maize & $0-8$ & $\geq 100$ & $\mathrm{sl}-\mathrm{c}$ & w & $5.6-7.5$ & Medium $(>\mathrm{N})$ & Low & None & $490-525$ \\
\hline Peanut & $\begin{array}{l}0-8 \\
\text { Range }^{f}\end{array}$ & $\geq 75$ & sl-cl & w & $6.0-7.5$ & Medium & Medium & None & $500-600$ \\
\hline Rice & $0-8$ & $10-50$ & & $\mathrm{p}-\mathrm{se}$ & $4.5-8.0$ & & & & \\
\hline Maize & $0-15$ & $50-100$ & sl-hc & i-se & $5.0-8.0$ & & & & \\
\hline Peanut & $0-8$ & $50-75$ & ls-cl & mw-se & $5.5-8.0$ & & & & \\
\hline
\end{tabular}

\footnotetext{
${ }^{\text {a }}$ Philippine Council for Agriculture and Natural Resources Research and Development.

${ }^{\mathrm{b}}$ Bureau of Soils and Water Management.

${ }^{c}$ Optimum value/range, which gives best result.

d sl: sandy loam; c: clay; ls: loamy sand; scl: sandy clay loam; cl: clay loam; hc: heavy clay.

e p: poorly drained; w: well drained; se: somewhat excessively drained; i: imperfectly drained; mw: moderately well drained.

${ }^{\mathrm{f}}$ The acceptable range for each land characteristics.
} 


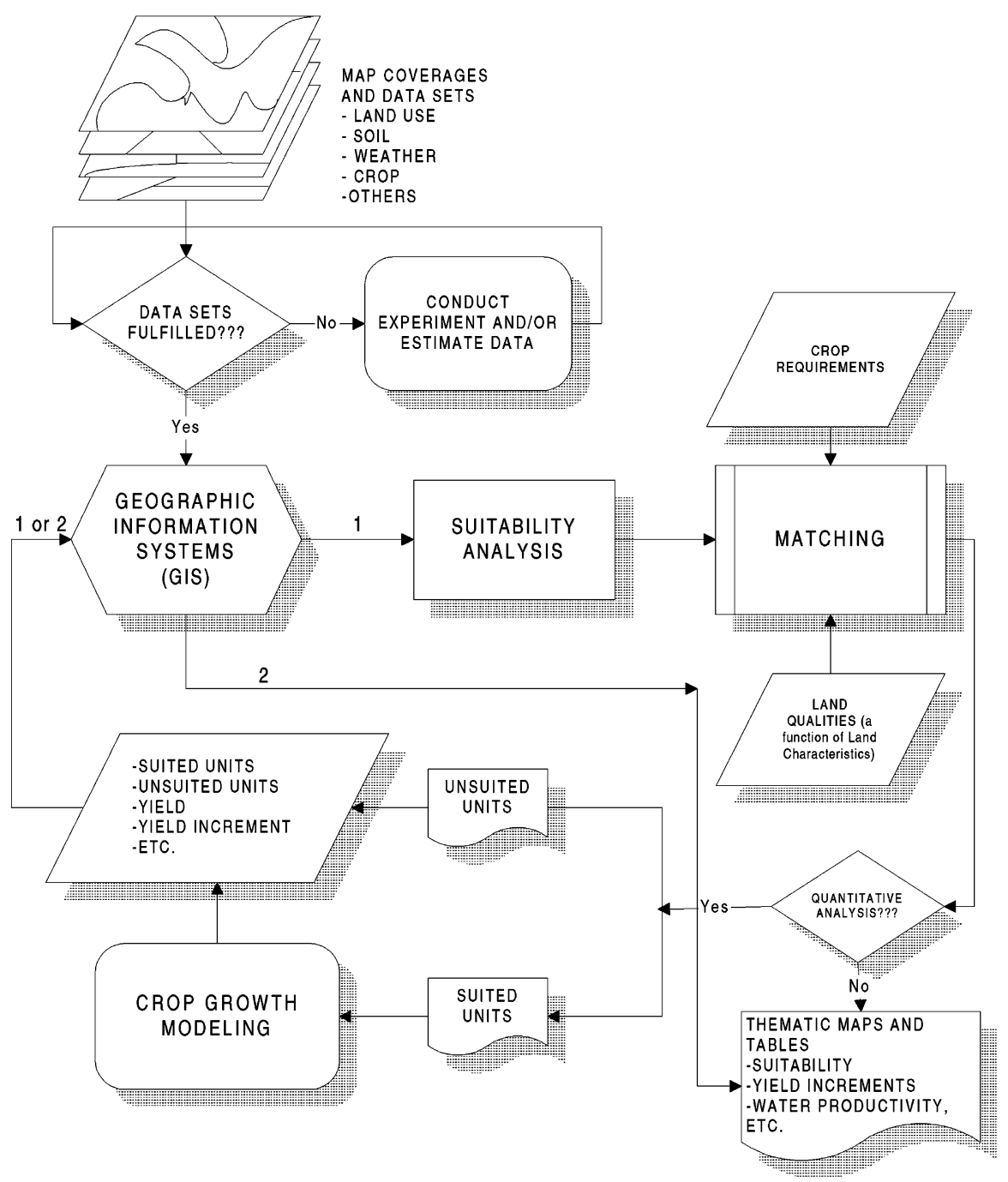

Fig. 2. Spatial analysis coupling GIS and crop growth models.

area. Then land suitability was classified as suitable and not suitable in general based on the mean of scores. The distinctions among the suitable areas were delineated using the quantitative results from crop modeling (Fig. 2). The suitability model presented here is static, hence, it is assumed that it does not vary from season to season (Ines, 1998).

\subsection{Description of the model}

The cereal models in DSSATv3.0 (Tsuji et al., 1994) are based on the CERES models (Ritchie et al., 1998). Only rice is unique among them because of its consideration of 
upland and lowland ecosystem. The CERES crop simulation models can predict the growth duration, average growth rates and the amount of assimilate partitioned to the economic yield components of the crops. They compute crop phasic and morphological development using temperature, day length and cultivar characteristics. Biomass growth is based on a radiation use efficiency (RUE) method, where the produced biomass is partitioned among the leaves, stems, roots, ears and grains. Biomass partitioning is based on the stage of development and the general growing conditions. The partitioning principles are based on source-sink concept, which are modified when water and nutrient deficiencies take place in the process. Crop yields are determined as a product of the grain numbers per plant and average kernel weight at physiological maturity. The number of grains is calculated from the above ground biomass growth during the critical stage in the growth process for a fixed thermal time before anthesis (Ritchie et al., 1998). The grain weight in all CERES models is calculated as a product of cultivar specific optimum growth rate and the duration of grain filling. Grain filling is reduced below the optimum if there is insufficient supply of assimilate from the daily produced biomass or the stored mobile biomass in the stem. When the growth is source limited, an inverse of partitioning will take place in the simulation where assimilates are redirected from the shoot to the roots. This occurs when the minimum fraction of daily biomass for root growth is exceeded. A detailed description of the CERES models can be seen in Ritchie et al. (1998). In this study, CERES-rice and CERES-maize were used in simulating rice and maize productions.

CROPGRO model on the other hand, is a compendium of models for legumes in DSSATv3.0. The model is process oriented and considers the crop carbon (C), crop and soil nitrogen $(\mathrm{N})$ and soil water balances. In DSSATv3.0 there is only one soil water balance and $\mathrm{N}$ model used by the crop models. The model computes canopy photosynthesis using daily leaf-level photosynthesis or hourly hedgerow light interception. It simulates the timing of the phenological stages as affected by temperature and day length. Dry matter partitioning is based on source-sink relationships during early vegetative growth and during reproductive growth. Partitioning during the later vegetative phase is based on empirical relations that vary by crop. The response function to temperature varies also during vegetative, early and late reproduction stage. In the $\mathrm{N}$ balance model, $\mathrm{N}_{2}$ fixation is accounted for where the root nodules fix available $\mathrm{N}$ in the atmosphere for the crop. The processes is different from CERES models because a detailed $\mathrm{C}$ balance is built in the model. The $\mathrm{C}$ losses of growth and maintenance respiration are also accounted for. The growth and development of the crops is based on the daily production of assimilates through photosynthesis then partitioned to the various plant organs, which proportions vary at different phenological stages (Boote et al., 1998; Jones et al., 1998). In the study, CROPGRO was used to model peanut production in the basin.

The soil water balance in DSSATv3.0 is based on Ritchie's model where the concept of upper drained and lower drained limits of soil water is used as a basis for the available water in the soil (Ritchie, 1981a,b). The approach is a simple water accounting in each layer considered in the soil profile (Ritchie, 1998). The water in the upper layer cascades to the lower layers mimicking the process of a series of linear reservoirs. Drainage takes place if the infiltration and the present soil water in the layer exceeds its water 
holding capacity. The drainage at the bottom of the profile is the drainage flux of the bottom layer. Upward flow can be caused by root water uptake due to transpiration and soil evaporation. Run-off is calculated using the modified USDA-SCS curve number method. The profile is assumed to be well drained, thus, no interaction with the groundwater. In the simulations, the modified Priestley-Taylor method was used in estimating evapotranspiration.

\subsection{The concept of production hierarchy}

In crop modeling, three levels of growth can be simulated; the potential, limited and reduced growths (Penning de Vries and van Laar, 1982; Penning de Vries et al., 1989; Hijmans et al., 1994). Correspondingly are their respective levels of yield, the potential, limited and reduced yields. Limited yield can be either water and/or nutrient limited. Crop models differ in handling the compounded effects of stresses that reduced the yield. Some uses the minimum value of the stresses, e.g. EPIC (Williams, 1995), while others use the product, e.g. SWAP (Van Dam et al., 1997) (in water or oxygen and salt stress). This conceptualization affects significantly the results of simulations. The DSSATv3.0 models use the minimum of stresses to reduce the quantity of the potential biomass produced per day (Ritchie, 1998; Godwin and Singh, 1998).

Potential production is the level of yield that a crop can achieve when the factors affecting crop growth are only radiation, temperature and plant properties. Other variables such as water and nutrients are considered in ample supply. Also, pests and diseases are minimal in effect. This is further referred to as the ideal irrigated production level. In this study, potential productions of the selected crops were simulated for every cropping season.

On the other hand, water-limited production is the level of yield that a crop can attain under limited water condition. In this study, this concept is considered as rainfed production. This scenario of growth can be modeled by introducing a water balance model to the growth model of potential production. The available water in the soil influences the rate of water uptake by the plants. Water stress develops as a result of limited available water, which is the driving force in the scenario and is affecting the growth process significantly. Although the weather is favorable, the limited water influences the photosynthetic activity. In situations where rainfall is abundant for the whole cropping season, the level of yield could reach the production ceiling. When $\mathrm{N}$ or other nutrients are also limited together with water, this could be generally called limited production level (Hijmans et al., 1994). In this paper, however, the term used when $\mathrm{N}$ and water are limiting is water-limited production without $\mathrm{N}$ application. Meaning, the soil water balance and N-simulation modules in DSSATv3.0 were activated but without irrigation and $\mathrm{N}$ application. The $\mathrm{N}$ processes are simulated; the source of $\mathrm{N}$ is the available $\mathrm{N}$ in the soil at the start of the cropping season.

Two scenarios were simulated under limited production; water-limited productions without and with $\mathrm{N}$ application. The $\mathrm{N}$ applied here was modeled as potential. To invoke this in the simulations, the $\mathrm{N}$-simulation module was not activated, therefore, behaving as water-limited production only. This is sought because it was difficult to quantify the $\mathrm{N}$ requirements and their distribution of applications for each of the crops, for each suitable 
land units, for the three cropping seasons (CS). This approach was thought to be adequate because the law of the minimum is applied in DSSATv3.0 models to estimate the daily actual biomass production. In this case, the $\mathrm{N}$ stress factor is always 1 and water stress factor could be less than or equal to 1 .

Moreover, reduced production is the level of yield where the quantity is mostly influenced by biotic factors, like pests and diseases.

\subsection{Definition of water productivity}

The three levels of water productivity defined by Molden (1997) are expressed by the following equations:

$$
\begin{aligned}
& \mathrm{PW}_{\text {inflow }}=C \frac{\text { yield }}{\text { net inflow }} \\
& \mathrm{PW}_{\text {depleted }}=C \frac{\text { yield }}{\text { depletion }} \\
& \mathrm{PW}_{\text {process }}=C \frac{\text { yield }}{\text { process depletion }}
\end{aligned}
$$

where PW is the water productivity $\left(\mathrm{kg} \mathrm{m}^{-3}\right)$, yield the actual yield $\left(\mathrm{kg} \mathrm{ha}^{-1}\right)$, net inflow the difference of the gross inflow and storage in the water balance equation $(\mathrm{mm})$, depletion the evapotranspiration $(\mathrm{mm})$, process depletion the transpiration alone $(\mathrm{mm})$ and $C$ is the conversion factor, 0.10 (ha $\mathrm{mm} \mathrm{m}^{-3}$ ).

Observing the equations above, the significance of irrigation is not delineated from the effect of effective rainfall. This term is promising to define because it will provide information on how irrigation water is used by the crops. Thus, the water productivity relative to irrigation is proposed. This is expressed as

$$
\begin{aligned}
& \mathrm{PW}_{\text {irrigation }}=C \frac{\Delta \text { yield }}{\Delta \text { depletion }} \\
& \Delta \text { yield }=\text { potential }- \text { rainfed } \\
& \Delta \text { depletion }=\text { potentialET }- \text { rainfedET }
\end{aligned}
$$

where potential is the potential production $\left(\mathrm{kg} \mathrm{ha}^{-1}\right)$, rainfed the rainfed production $\left(\mathrm{kg} \mathrm{ha}^{-1}\right)$, potentialET is the potential evapotranspiration $(\mathrm{mm})$ and rainfedET the evapotranspiration under rainfed condition ( $\mathrm{mm})$.

The numerator in Eq. (2.4) is what is called the incremental productivity, which is the difference of the potential and water-limited yields. In the study, the incremental productivity of the two water-limited scenarios were determined in each of the suitable land units in every cropping season.

The denominator is the incremental water requirement, the difference between the potential $\left(\mathrm{ET}_{\mathrm{p}}\right)$ and the actual crop evapotranspiration $\left(\mathrm{ET}_{\mathrm{a}}\right)$. Theoretically, this is the differential water demand needed to achieve production ceiling. In this study, water productivity is based only on a crop water requirement standpoint. 


\subsection{Initial conditions and input data}

Three CS were considered in the simulations: (1) October 1996-January 1997, (2) January-May 1997, and (3) May-September 1997. The sowing dates for each of the cropping season were 5 October, 30 January and 26 May; the same for all selected crops. The water regime in the soil was initially at upper limits and the fertility was the fertility level during data collection. Updated soil data especially fertility is important. For this study most of the spatial data were collected from secondary sources (BSWM, 1990; JICA, 1996). Field visits were also conducted for reconnaissance survey.

Spatial analysis was done in a vector based GIS, the PC ARC/INFO (ESRI, 1994). Maps of soils, slope, soil depth, fertility, erosion, agro-climatic, flood hazard, soil physiography and land use were converted to digital form and used in the analysis.

Soil properties were derived from USDA-SCS database in DSSATv3.0 (Tsuji et al., 1994). Soil classifications for each suitable land units were matched in the database to acquire detailed soil data for the crop models. This is the simplest way to estimate the soil specific parameters if there is no other way to figure it out. In this study, since soil data were gathered from secondary sources, using the soil utility program in DSSATv3.0 was a fair option.

The cultivars used were IR-64 for rice, PIO 3541 for maize and TAMNUT for peanut. The genetic properties of these varieties were as well taken from DSSATv3.0 database (Tsuji et al., 1994). Cultural management data were gathered from the recommends of rice, maize and peanut in the Philippines' setting (PCARRD, 1989a-c).

Furthermore, daily data on: rainfall, solar radiation (SRAD), maximum and minimum temperature from 1996 to 1997 were gathered from nearby meteorological stations. However, only one set of weather data (from one station) was used for the whole basin since it is impractical to establish daily weather information for each of the suitable land units. This assumption may be appropriate to SRAD but may result in more significant errors for the other data.

\section{Results and discussion}

\subsection{Weather data}

Fig. 3a and b show the weather pattern in the basin from 1996 to 1997 . Notice that 1996 was a wet year with a total rainfall of $2844 \mathrm{~mm}$ while 1997 was relatively dry with a total rainfall of $1170 \mathrm{~mm}$. Moreover, CS 1 can be considered as relatively wet because of the rainfall of October and November 1996, CS 2 falls to the dry period of the year while CS 3 falls to the wet season. CS 1-3 had a rainfall of 557, 171 and $903 \mathrm{~mm}$, respectively (Table 2). The rainfall in CS 1 occurred only during the first 45 days while in CS 2 it occurred only during the month of May and was more uniformly distributed during CS 3 . SRAD peaks during the dry season and the maximum temperature varied from 31 to $33{ }^{\circ} \mathrm{C}$ in a year. The minimum temperature is more variable throughout the year where it starts to fall in November within the order of $18-20^{\circ} \mathrm{C}$ and starts to increase MarchApril. 

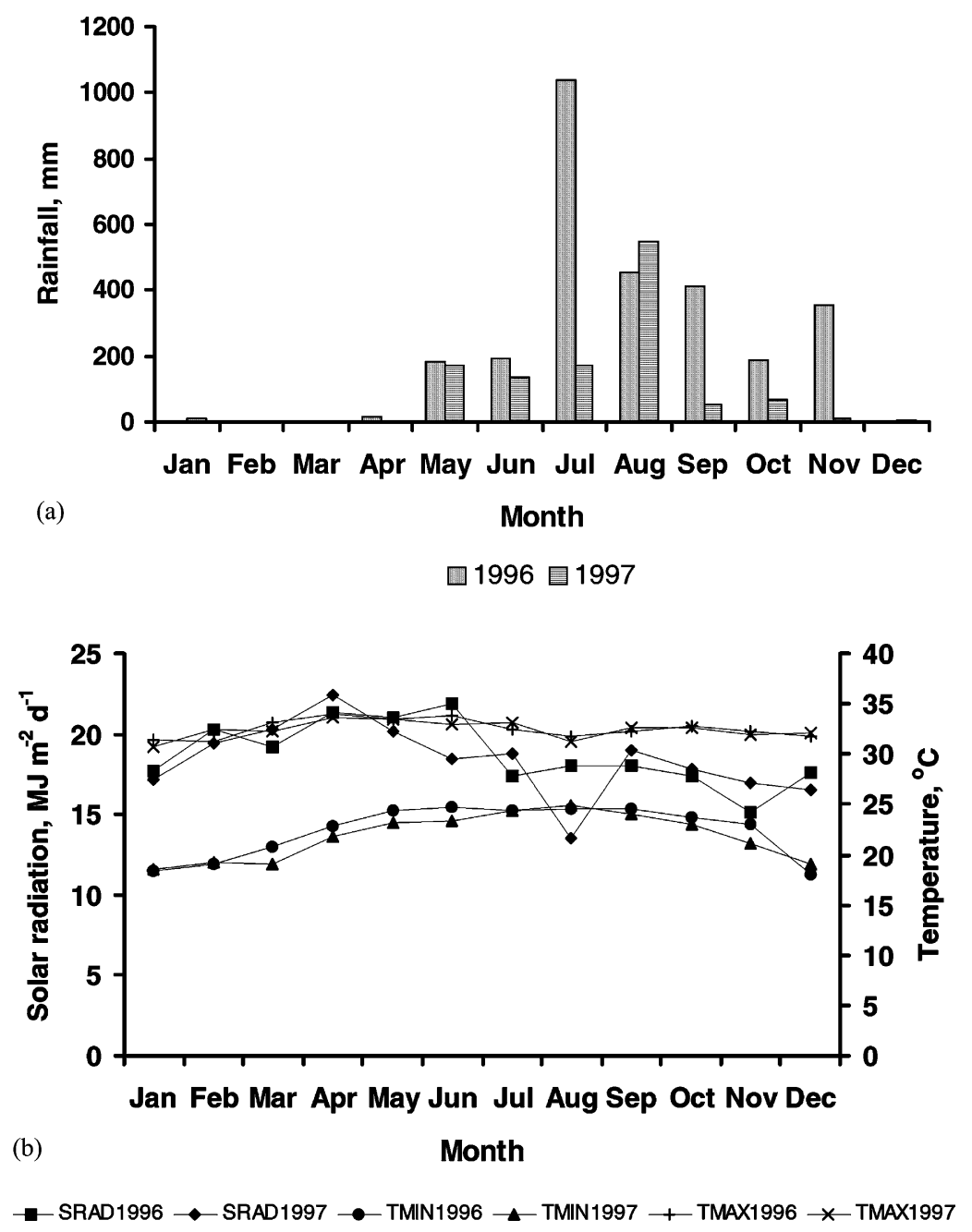

Fig. 3. (a) Rainfall distribution in the study area: 1996-1997. (b) Average SRAD, maximum and minimum temperature ( $\left.T_{\text {MAX }}, T_{\text {MIN }}\right)$ in the study area: 1996-1997.

\subsection{Productivity potentials}

The suitable areas for rice, maize and peanut were delineated in the river basin. These land units are composed of the existing and potential agricultural areas. The result showed that an average of $27 \%$ of the basin is suitable for the selected crops, the suitable areas for maize is a bit greater than rice and peanut. Approximately $2 \%$ of the basin comprises the potential agricultural areas based from the approach above. Most land areas in the basin are not suitable for the selected crops.

Because of the assumption that weather is homogenous in the basin, the potential productions of the selected crops do not vary along the basin within a cropping season. 
Table 2

The total rainfall, average SRAD, maximum and minimum temperature during the growing periods

\begin{tabular}{lrrr}
\hline Climatic variables & CS $^{\mathrm{a}} 1$ & CS 2 & CS 3 \\
\hline Rainfall $(\mathrm{mm})$ & 556.8 & 171.4 & 903.4 \\
SRAD $\left(\mathrm{MJ} \mathrm{m}{ }^{-2}\right.$ per day) & 16.8 & 20.8 & 17.5 \\
Maximum temperature $\left({ }^{\circ} \mathrm{C}\right)$ & 31.9 & 33.0 & 32.5 \\
Minimum temperature $\left({ }^{\circ} \mathrm{C}\right)$ & 20.8 & 20.7 & 24.2 \\
\hline
\end{tabular}

${ }^{\mathrm{a}}$ Cropping season.

However, it is evident in Fig. 4 that potential productions vary along the CS in the basin. The maximum production levels that rice, maize and peanut can achieve are 5722, 7135 and $4126 \mathrm{~kg} \mathrm{ha}^{-1}$ for CS 1; 7226, 8154 and $4466 \mathrm{~kg} \mathrm{ha}^{-1}$ for CS 2; 5855, 6819 and $2989 \mathrm{~kg} \mathrm{ha}^{-1}$ for CS 3. It can be observed that during CS 2, the potential production of the crops is highest among the rest of the CS. This is attributed to the higher SRAD (see Table 2 and Fig. 3) in the growing period. It is also interesting to note that of the three crops, maize performed more superior compared to rice and peanut. Maize is a $\mathrm{C}_{4}$ crop where the other two are $\mathrm{C}_{3} ; \mathrm{C}_{4}$ are more photosynthetically efficient than $\mathrm{C}_{3}$ crops, they convert the photosynthetically active radiation (PAR) into assimilates far better than the latter (Penning de Vries et al., 1989).

Water-limited production, as defined earlier, is the level of yield that a crop can attain when water is a constraint in the growth process. Implied in the definition that the available water in the soil, and sometimes in the plants, could not match the evaporative demand of the atmosphere. The actual crop evapotraspiration is often below the potential $\left(\mathrm{ET}_{\mathrm{a}}<\mathrm{ET}_{\mathrm{p}}\right)$ resulting in water stress during the growing period. Water stress in the critical periods of crop growth drastically affects the level of production. In contrast, water stress in non-critical periods does not significantly affect the growth process.

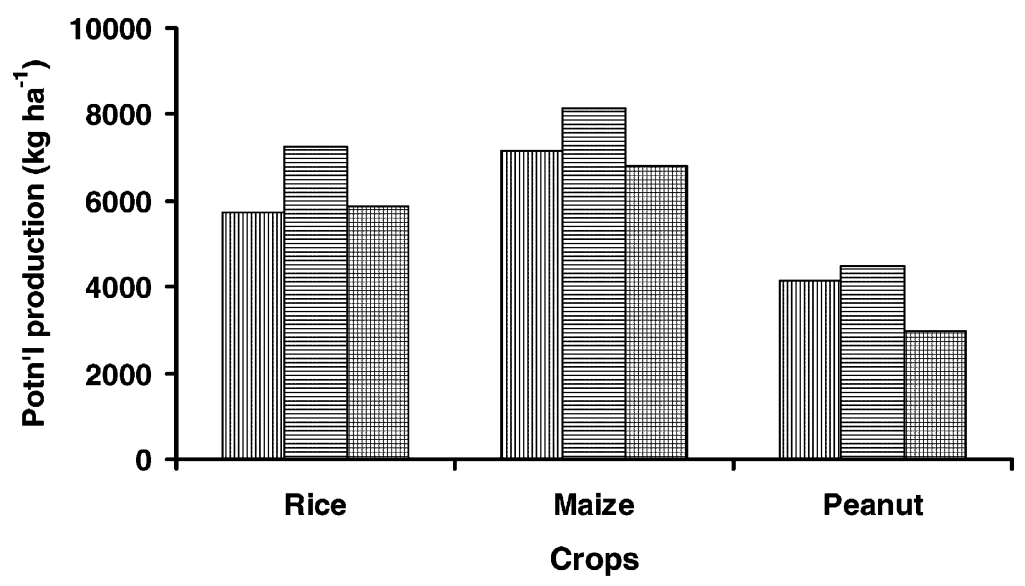

四CS 1 目CS 2 瞒CS 3

Fig. 4. Potential productivity of the selected crops for different CS. 
Table 3

Water-limited productivity $\left(\mathrm{kg} \mathrm{ha}^{-1}\right)$

\begin{tabular}{|c|c|c|c|c|c|c|c|c|c|}
\hline \multirow[t]{2}{*}{ Statistics } & \multicolumn{3}{|l|}{ CS 1} & \multicolumn{3}{|l|}{ CS 2} & \multicolumn{3}{|l|}{ CS 3} \\
\hline & Rice & Maize & Peanut & Rice & Maize & Peanut & Rice & Maize & Peanut \\
\hline \multicolumn{10}{|c|}{ (a) With optimum $\mathrm{N}$} \\
\hline Average & 1055.9 & 6384.2 & 1366.2 & 1191.8 & 1150.9 & 20.6 & 5495.1 & 6792.7 & 2932.6 \\
\hline S.D. ${ }^{a}$ & 348.7 & 624.1 & 507.8 & 326.9 & 1280.6 & 62.0 & 247.0 & 67.4 & 42.7 \\
\hline Maximum & 1918.0 & 7135.0 & 2948.0 & 1928.0 & 5251.0 & 279.0 & 5810.0 & 6819.0 & 2989.0 \\
\hline Minimum & 572.0 & 5143.0 & 697.0 & 538.0 & 42.0 & 0.0 & 4866.0 & 6590.0 & 2850.0 \\
\hline \multicolumn{10}{|l|}{ (b) Without $\mathrm{N}$} \\
\hline Average & 634.0 & 944.9 & 452.9 & 89.8 & 360.9 & 20.8 & 1559.5 & 1290.0 & 661.1 \\
\hline S.D. ${ }^{\mathrm{a}}$ & 336.7 & 640.1 & 313.5 & 172.1 & 109.1 & 41.2 & 965.5 & 636.8 & 244.0 \\
\hline Maximum & 1669.0 & 2742.0 & 1336.0 & 512.0 & 605.0 & 154.0 & 3844.0 & 2913.0 & 1190.0 \\
\hline Minimum & 122.0 & 203.0 & 139.0 & 0.0 & 226.0 & 0.0 & 82.0 & 364.0 & 181.0 \\
\hline
\end{tabular}

${ }^{\text {a }}$ Standard deviation.

When water is adequate during the critical periods, the yield is not significantly impacted (Doorenbos and Kassam, 1979). In general, this level of production has only rainfall, water available in the soil matrix and capillary rise as the sources of water for the plants. The capillary rise, however, is not simulated by DSSATv3.0 because the soil column is assumed as well drained. Table $3 \mathrm{a}$ and $\mathrm{b}$ show the water-limited productivity with and without $\mathrm{N}$ applications, of the selected crops in the basin at different CS (see Section 2.4 for definitions).

During CS 1, the water-limited yield of rice with optimum nitrogen requirements varied from 572 to $1918 \mathrm{~kg} \mathrm{ha}^{-1}$. Although rainfall in this season is $557 \mathrm{~mm}$, the levels of yield still imply that the crop suffered significant water stress, which obviously occurred during the critical periods of crop growth. The timing of rainfall is the major factor that influenced the level of yield. The same is true with peanut; water stress was significant, the yield varied from 697 to $2948 \mathrm{~kg} \mathrm{ha}^{-1}$. However, maize is an exception, the average yield in the basin was $6384 \mathrm{~kg} \mathrm{ha}^{-1}$ with minimum and maximum yields of 5143 and $7135 \mathrm{~kg} \mathrm{ha}^{-1}$, respectively; some land units achieved the potential production. This performance is attributed to the rooting depth of the crop.

It is apparent that during the dry period of the year (CS 2), where rainfall is $171 \mathrm{~mm}$ for 4 months, the selected crops did not perform well as expected. Average yields of rice, maize and peanut in the basin were 1192,1151 and $21 \mathrm{~kg} \mathrm{ha}^{-1}$, respectively. The effect of higher SRAD is observed in the yield levels. Rainfall only occurred during the month of May and for the first 3 months of growth, the only sources of water for the plants were the soil water available. The soil water was at its upper limits when sowing commenced. Moreover, for maize, the effect of rooting depth is still prevalent in some land units. For peanut, however, there was almost no yield achieved in most of the suitable land units in the basin.

With a rainfall of $903 \mathrm{~mm}$ for the whole of CS 3, fairly uniformly distributed, resulted to the excellent crop yield. Most of the suitable land units achieved potential productions of maize and peanut. The maximum yield achieved by rice was 5810 while its potential is 
$5855 \mathrm{~kg} \mathrm{ha}^{-1}$. This is attributed to the higher water requirement of rice compared to maize and peanut. The yields did not vary greatly from each of the suitable land units.

Furthermore, the consequence of nitrogen deficiency in crop growth when water is limited is evident (Table 3b). There were certain levels of yield realized during CS 1 and 3 , however, crop growth during CS 2 is almost not possible. Unusual results occurred to some land units during CS 2 where the yield of maize when water and $\mathrm{N}$ are limited increased compared to the case with optimum $\mathrm{N}$. This may be the limitation of the model under extreme environmental stress. A hypothesis though can be postulated. Under this particular soil, as the plants are subjected to water and $\mathrm{N}$ limitations, they proliferated their roots in search for water and nutrients. It is established in experimental observations that mobilization of assimilates from shoot to roots take place when the growth is source limited (Ritchie et al., 1998). Likewise, under water-limited condition only (with optimum N), the crops in this particular soil did the same but the motivation is only to search for water. The improved performance of the crop could be attributed to an increased uptake of water when rainfall came at the later part of the cropping season. It is believed that due to the compounded motivation under $\mathrm{N}$ and water-limited conditions there were more densed roots produced than the one with only one driving force, in this particular land unit. This was also observed in peanut simulation.

\subsection{The productivity of water}

The productivity of water was determined by defining two differential variables, i.e. incremental productivity and incremental water requirements. The greater the incremental productivity, the lower the actual production. In Table 4, it is evident that when water is the growth constraint, the yield gap is high and much more when nutrient is deficient in the soil. When rainfall is adequate and fell uniformly distributed during the growing season, the yield gap can be minimal. Water is needed in nutrient dynamics, hence, the process is suppressed when water is limited. Fig. 5a-c show the spatial distributions for rice in the basin during CS $1-3$, respectively.

The model was capable to account for the spatial differences of incremental water requirements. Generally, it was observed that with optimum nitrogen supply, the crops are more active to extract water from the soil throughout the growth process. During development and midseason stage, plants are so demanding with water that they attempt to satisfy this requirement. Given the condition where water is applied or present in the soil, water use is tremendous. On the other hand, plants with deficiency of nitrogen are less active and more sensitive to water stress. Crops ended with premature growth or even

Table 4

Average incremental productivity $\left(\mathrm{kg} \mathrm{ha}^{-1}\right)$ in the basin

\begin{tabular}{|c|c|c|c|c|c|c|c|c|c|}
\hline \multirow[t]{2}{*}{ Parameters } & \multicolumn{3}{|l|}{ CS 1} & \multicolumn{3}{|l|}{ CS 2} & \multicolumn{3}{|l|}{ CS 3} \\
\hline & Rice & Maize & Peanut & Rice & Maize & Peanut & Rice & Maize & Peanut \\
\hline Due to irrigation & 4666.1 & 750.8 & 2759.8 & 6034.2 & 7003.1 & 4445.5 & 361.2 & 26.3 & 56.4 \\
\hline Due to irrigation and $\mathrm{N}$ & 5088.1 & 6190.1 & 3670.2 & 7136.2 & 7793.1 & 4445.2 & 4296.9 & 5529.0 & 2327.9 \\
\hline Potential production $\left(\mathrm{kg} \mathrm{ha}^{-1}\right)$ & 5722.0 & 7135.0 & 4126.0 & 7226.0 & 8154.0 & 4466.0 & 5855.0 & 6819.0 & 2989.0 \\
\hline
\end{tabular}


death if water is not enough to support their physiological needs. Usually, this happened during CS 2 (see Table 3). Maize is an exception because of its rooting depth; it can extract soil water redistributed in the soil profile. Table 5 shows the incremental water requirements of the selected crops in different CS. The table only presents the differential requirements with optimum $\mathrm{N}$ as it emphasizes the significance of irrigation more. The greater the difference means the lesser the actual crop evapotranspiration.

The timing of rainfall is significant in all CS. In CS 1, where the total rainfall was $557 \mathrm{~mm}$, still water stress exists, especially to the shallow rooted crops. Most of the rainfall in this season fell during the first 45 days after sowing. The plants were stressed during midseason to maturity stage of the growth process. It should be noted that water loss was not only through evapotranspiration but also through run-off and drainage. The remaining was stored in the soil and redistributed. There were higher requirements during the dry period and lesser in the wet season. Interestingly, land units that achieved the

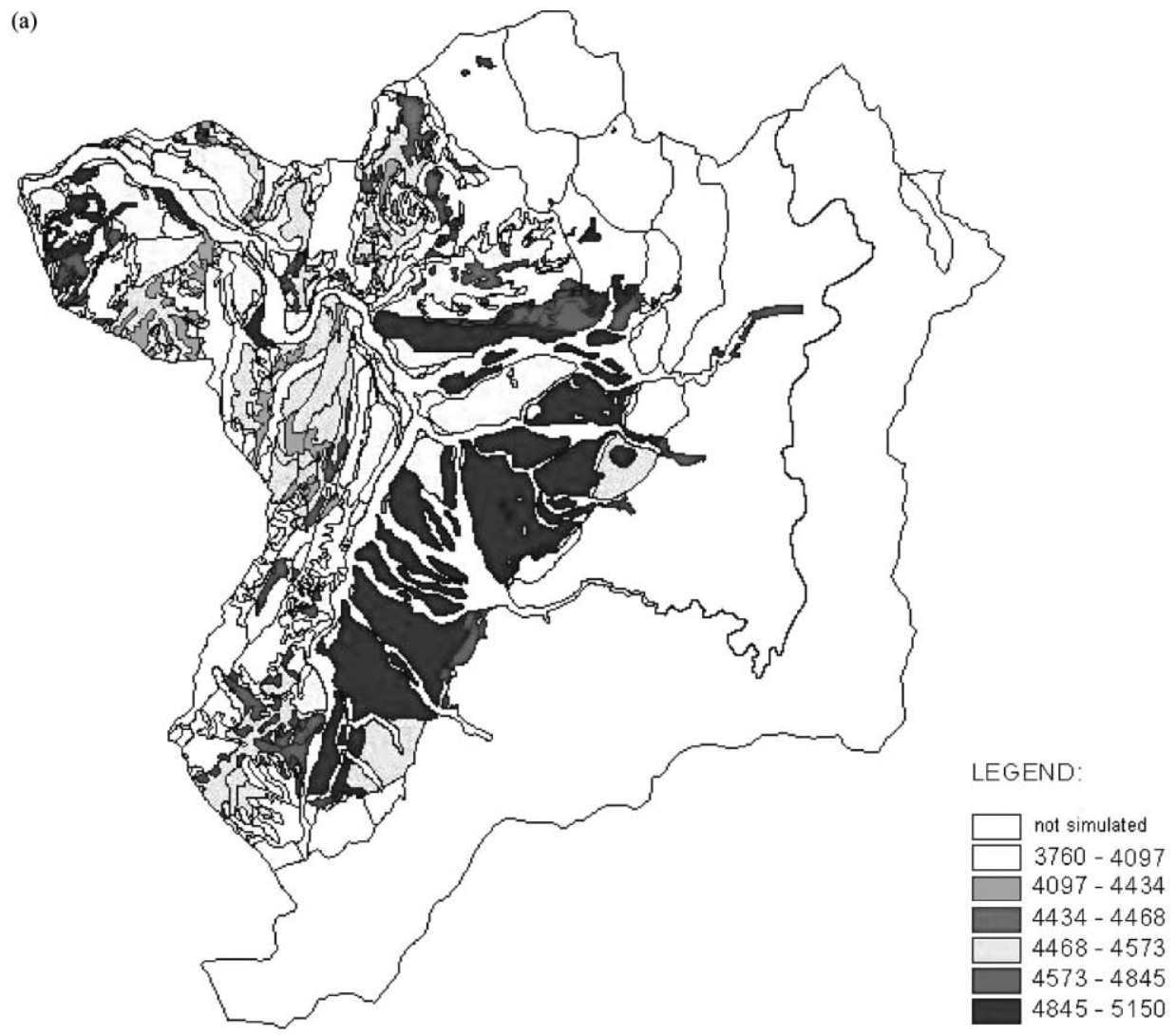

Fig. 5. (a) Incremental productivity of rice due to irrigation during CS 1. (b) Incremental productivity of rice due to irrigation during CS 2. (c) Incremental productivity of rice due to irrigation during CS 3 . 


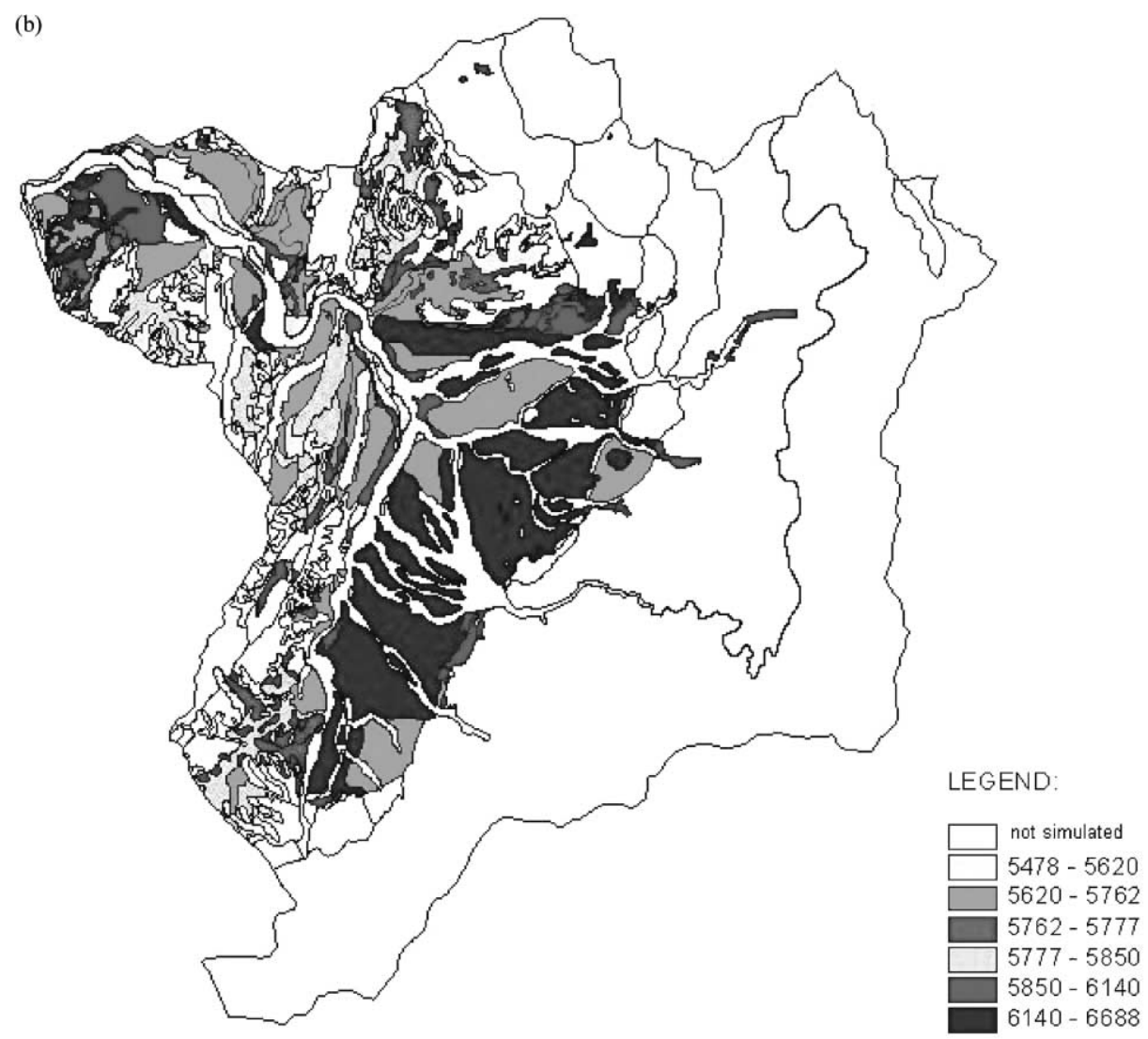

Fig. 5. (Continued).

production ceiling when water was adequate have still incremental water requirements. This is attributed to the non-beneficial loss of water from evapotranspiration, i.e. the soil evaporation $\left(E_{\text {soil }}\right)$. With the quantity of water available, it fully met the physiological needs of the crops but some quantity of water has to be replenished to fully meet the atmospheric demand. The model is capable in partitioning soil evaporation and plant transpiration but the combination of two was used, as it is the basis of irrigation requirements.

The preceding discussion did not reveal explicitly the mass of product produced from the marginal water to be applied. The unit mass of produce per unit of water has more implication in general because it gives a more direct measure on the importance of water in time and space. On the average, during CS 1, this index was on the order of $1.2 \mathrm{~kg} \mathrm{~m}^{-3}$ for rice and peanut while maize had $0.54 \mathrm{~kg} \mathrm{~m}^{-3}$; during CS 3, the marginal benefit was minimal (Table 6). CS 2 has an interesting implication; previous analysis shows that crop 


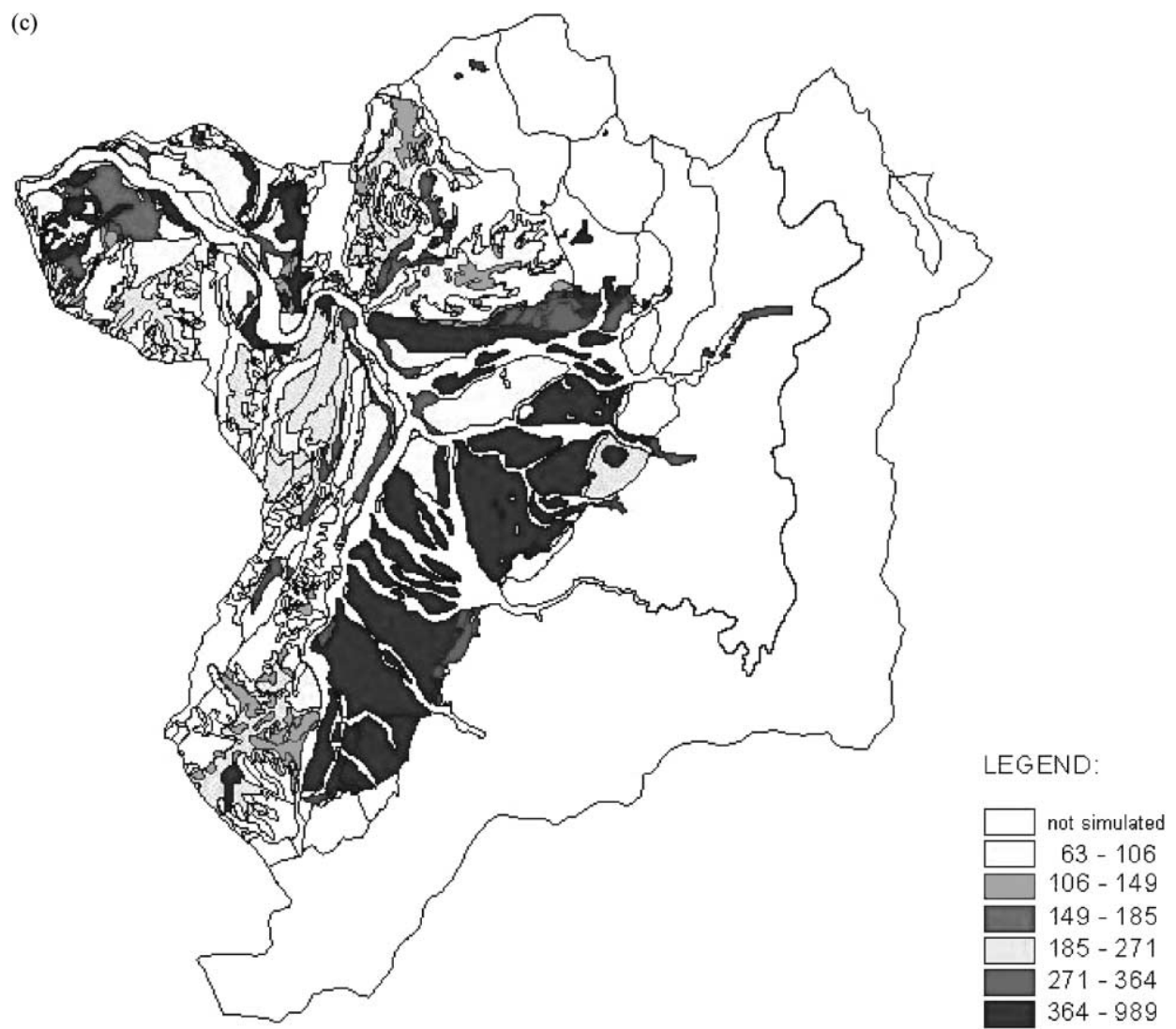

17

0

34 Kilom eters

Fig. 5. (Continued).

production during this season is the highest because of higher SRAD. However, the reward is expensive as it entails larger water quantity because of higher water demand. For rice and peanut, an average of 675 and $446 \mathrm{~mm}$ water only yielded to 0.89 and $1.01 \mathrm{~kg} \mathrm{~m}^{-3}$, respectively. For maize, with $229 \mathrm{~mm}$ water it had a return of $3.12 \mathrm{~kg} \mathrm{~m}^{-3}$.

Table 5

Incremental water requirements $\left(\mathrm{m}^{3} \mathrm{ha}^{-1}\right)$ in the basin

\begin{tabular}{|c|c|c|c|c|c|c|c|c|c|}
\hline \multirow[t]{2}{*}{ Statistics } & \multicolumn{3}{|l|}{ CS 1} & \multicolumn{3}{|l|}{ CS 2} & \multicolumn{3}{|l|}{ CS 3} \\
\hline & Rice & Maize & Peanut & Rice & Maize & Peanut & Rice & Maize & Peanut \\
\hline Average & 4004.2 & 1236.4 & 2283.5 & 6744.0 & 2293.9 & 4459.7 & 2206.2 & 701.4 & 1037.2 \\
\hline S.D. & 338.8 & 228.3 & 229.5 & 329.8 & 356.6 & 445.0 & 253.5 & 108.0 & 118.9 \\
\hline Maximum & 4530.1 & 1668.6 & 2664.0 & 7472.6 & 3313.4 & 5171.0 & 2804.3 & 836.1 & 1302.0 \\
\hline Minimum & 3186.9 & 781.8 & 1673.4 & 6014.3 & 1966.1 & 3534.5 & 1828.5 & 415.9 & 775.9 \\
\hline
\end{tabular}


Table 6

Water productivity $\left(\mathrm{kg} \mathrm{m}^{-3}\right)$ in the basin

\begin{tabular}{|c|c|c|c|c|c|c|c|c|c|}
\hline \multirow[t]{2}{*}{ Statistics } & \multicolumn{3}{|l|}{ CS 1} & \multicolumn{3}{|l|}{ CS 2} & \multicolumn{3}{|l|}{ CS 3} \\
\hline & Rice & Maize & Peanut & Rice & Maize & Peanut & Rice & Maize & Peanut \\
\hline Average & 1.17 & 0.54 & 1.20 & 0.89 & 3.12 & 1.01 & 0.15 & 0.04 & 0.05 \\
\hline S.D. & 0.04 & 0.39 & 0.14 & 0.01 & 0.74 & 0.10 & 0.08 & 0.09 & 0.04 \\
\hline Maximum & 1.29 & 1.19 & 1.39 & 0.92 & 3.94 & 1.26 & 0.35 & 0.30 & 0.11 \\
\hline Minimum & 1.11 & 0.00 & 0.70 & 0.88 & 1.29 & 0.86 & 0.02 & 0.00 & 0.00 \\
\hline
\end{tabular}

This is interesting to scrutinized because this gives a glimpse on how water use should be planned and managed. This performance of maize is attributed to its properties as a $\mathrm{C}_{4}$ crop, cultivar characteristics and rooting depths. A caution though should be considered in the analysis because a zero value does not imply that there is no need to apply water.

This water productivity index indicates the significance of irrigation during a cropping season. If it is less likely that irrigation is desired because rainfall is adequate for the crops, the available water could be saved and allocated to other purpose. Unfortunately in this basin, there is no storage dam available. The index also implies the effective use of the water available in the soil profile.

Of course, it always leads to the planning stage. Where infrastructure is available to control the supply of water to be delivered for irrigation, this index could be of advantage. The challenge here is how to predict the rainfall for the coming CS. Weather predictors are available but still there is no better than the real-time data because these methods are also based on stochastic or heuristic approach. Notwithstanding, at least a probable rainfall distribution could be established. Then, the return from irrigation could be estimated, and opportunities of water saving could be explored.

\subsection{Benefit of irrigation}

The law of the minimum is the driving force in DSSATv3.0 models when crop growth is source limited. When water availability determines crop growth, the benefit of irrigation dominates the total benefit; the same is true when $\mathrm{N}$ availability limits the growth. Using Table 4, the estimates of irrigation and $\mathrm{N}$ benefits were derived. $\mathrm{N}$ benefit is estimated by getting the difference between the two incremental productivity terms. Irrigation is beneficial during CS 1 and 2 while it is marginally beneficial during CS 3 . The performance of maize and peanut during CS 1 and 2, respectively, gives a good panorama on crops responses to their environment. For maize, only $11 \%$ of the benefit is contributed by irrigation while $76 \%$ by nitrogen. There was lesser importance of irrigation because of its rooting depth. For peanut, most of the benefit comes from irrigation $(99.5 \%)$ because the crop can synthesize its own $\mathrm{N}$ requirement from atmospheric nitrogen through their root nodules (Table 7). Further, CS 3 has clearer implication: the marginal benefit from irrigation is low, meaning the expected level of crop production is high with the available rainfall as long as the $\mathrm{N}$ requirements of the crops are met accordingly. 
Table 7

Average benefit of irrigation and $\mathrm{N}(\%)$ in the basin

\begin{tabular}{|c|c|c|c|c|c|c|}
\hline \multirow{2}{*}{$\begin{array}{l}\text { Cropping } \\
\text { season }\end{array}$} & \multicolumn{3}{|c|}{ Benefit of irrigation } & \multicolumn{3}{|c|}{ Benefit of $\mathrm{N}$ application } \\
\hline & Rice & Maize & Peanut & Rice & Maize & Peanut \\
\hline CS 1 & 81.6 & 10.5 & 66.9 & 7.4 & 76.2 & 22.1 \\
\hline CS 2 & 83.5 & 85.9 & 99.5 & 15.3 & 9.7 & 0.0 \\
\hline CS 3 & 6.2 & 0.4 & 1.9 & 67.2 & 80.7 & 76.0 \\
\hline
\end{tabular}

\section{Conclusions}

This paper presented an example of a spatio-temporal analysis of water productivity using a combination of GIS and crop growth simulation models. The combination of the two enabled a more effective analysis because the spatial and temporal dimensions are studied at once, hence, broader understanding about the implications of the indices under investigation.

The crop level analysis using crop growth models gave a clearer understanding to the interactions of the crop, weather and water. The concept of production hierarchy can be used to delineate the effects of water and $\mathrm{N}$ in a growing period, which could be repeated along the CS.

The spatial differences can be accounted in a GIS, which enables one to see the where and what of the water productivity indices being studied.

Results showed that potential production of the selected crops vary along the CS in the basin. This is high during the dry season, however, this could be too expensive to achieve because of higher water requirement. But this might be compensated through selecting the crops or crop varieties to be planted or by minimizing the loss of water from soil evaporation. During wetter periods, the potential of rainfall in crop production is emphasized in the analysis.

The water-limited productions vary along the suitable land units, within a cropping season. During wetter periods, the selected crops could produce significant yields without irrigation. However, crop growth is almost not possible during the dry season. When $\mathrm{N}$ is limited along with water, the lesser is the expected productions.

The water productivity index developed here is more on evaluating the significance of irrigation in a cropping season. This is a strong index because the value of irrigation is evaluated prior to the cropping season. Water saving strategies could be synchronized with the analysis.

In this study, the water productivity (irrigation) was found to be low during the wet season, further analysis showed that the expected level of yield is high as long as the $\mathrm{N}$ requirements of the crops are fully met. Rainfall could be adequate to support the water requirements of the crops for the growing season. This further substantiates the role of irrigation as supplemental during the wet season, but sometimes, in reality, it is not.

Several lessons that can be learned from the analysis are as follows.

- Deficit irrigation could be an alternative to save water in water scarce areas. Water stress during non-critical periods of crop growth does not impact significantly to the yield. 
- There is always the need of improved methodology in predicting weather parameters, which would permit better analysis of $\mathrm{PW}_{\text {irrigation. This water productivity index is an }}$ estimate to the value of irrigation during a cropping season.

- To save water, take advantage of the rainfall, adjusting the cropping calendar could be of advantage. In this case, careful planning and scheduling of the water releases from the storage facility could save significant volume of water for other purpose. Water harvesting at the on-farm level is another strategy of saving water for other use. Also, the antecedent soil moisture is a potential resource in agriculture. This should be taken into consideration. And last but not the least, the selection of crops or varieties of crops. Drought resistant crops could be planted during the dryer periods. Deep-rooted crops could also be selected to take advantage of the antecedent soil moisture.

\section{Acknowledgements}

The authors wish to acknowledge Mr. Charles L. Abernethy for his comments and suggestions in the study, also to the late Dr. Gunner K. Hansen for sharing his expertise in crop modeling.

\section{References}

Boote, K.J., Jones, J.W., Hoogenboom, G., Pickering, N.B., 1998. The CROPGRO model for grain legumes. In: Tsuji, G.Y., Hoogenboom, G., Thornton, P.K. (Eds.), Understanding Options of Agricultural Production. International Consortium for Agricultural Systems Applications, Kluwer Academic Publishers, Dordrecht, The Netherlands, pp. 99-128.

BSWM, 1990. Physical Land Resources of Ilocos Norte (With Maps). Manila, Philippines.

Droogers, P., Bastiaanssen, W.G.M., Beyazgül, M., Kayam, Y., Kite, G.W., Murray-Rust, H., 2000. Distributed agro-hydrological modeling of an irrigation system in Western Turkey. Agric. Water Manage. 43, $183-202$.

Droogers, P., Kite, G., 2001. Estimating Productivity of Water at Different Spatial Scales Using Simulation Modeling. Research Report No. 53, International Water Management Institute, Colombo, Sri Lanka, 16 pp.

Doorenbos, J., Kassam, A.H., 1979. Yield Response to Water. Report No. 33, FAO, Rome.

ESRI, 1994. PC ARC/INFO. Redlands, CA, USA.

Godwin, D.C., Singh, U., 1998. Nitrogen balance and crop response to nitrogen in upland and lowland cropping systems. In: Tsuji, G.Y., Hoogenboom, G., Thornton, P.K. (Eds.), Understanding Options of Agricultural Production. International Consortium for Agricultural Systems Applications, Kluwer Academic Publishers, Dordrecht, The Netherlands, pp. 55-77.

Hijmans R.J., Guiking-Lens, I.M., Van Diepen, C.A., 1994. WOFOST 6.0. Users' Guide for WOFOST 6.0: Crop Growth Simulation Model. SC-DLO, Wageningen, The Netherlands.

Ines, A.V.M., 1998. Land use options using simulation and systems analysis: a case study of the Laoag River Basin, Ilocos Norte, Philippines. Master of Engineering Thesis, Asian Institute of Technology, Bangkok, Thailand.

Ines, A.V.M., 1999. Integration of Geographic Information Systems with Crop Models: Special Study (unpublished). Asian Institute of Technology, Bangkok, Thailand.

JICA, 1996. Feasibility Study of SABO Dam, Laoag River Basin, Ilocos Norte, Philippines. Final Report, Japan. Jones, J.W., Tsuji, G.Y., Hoogenboom, G., Hunt, L.A., Thornton, P.K., Wilkens, P.W., Imamura, D.T., Bowen, W.T., Singh, U., 1998. Decision support system for sagrotechnology transfer: DSSATv3.0. In: Tsuji, G.Y., Hoogenboom, G., Thornton, P.K. (Eds.), Understanding Options of Agricultural Production. International Consortium for Agricultural Systems Applications, Kluwer Academic Publishers, Dordrecht, The Netherlands, pp. 157-177. 
Molden, D., 1997. Accounting for water use and productivity. SWIM Paper, Vol. 1. International Irrigation Management Institute, Colombo, Sri Lanka, 16 pp.

PCARRD, 1986. Environmental Adaptation of Crops. PCARRD, Los Baños, Laguna, Philippines.

PCARRD, 1989a. Philippine Recommends for Corn. PCARRD, Los Baños, Laguna, Philippines.

PCARRD, 1989b. Philippine Recommends for Peanut. PCARRD, Los Baños, Laguna, Philippines.

PCARRD, 1989c. Philippine Recommends for Rice. PCARRD, Los Baños, Laguna, Philippines.

Penning de Vries F.W.T., van Laar, H.H., 1982. Simulation of Plant Growth and Crop Production. Center for Agricultural Publishing and Documentation, Wageningen, The Netherlands.

Penning de Vries, F.W.T., Jansen, D.M., ten Berge, H.F.M., Bakema, A., 1989. Simulation of ecophysiological processes of crop growth in several annual crops. Simulation Monograph. Pudoc, Wageningen, The Netherlands.

Ritchie, J.T., 1981a. Water dynamics in the soil-plant-atmosphere. Plant and Soil 58, 81-96.

Ritchie, J.T., 1981b. Soil water availability. Plant and Soil 58, 327-338.

Ritchie, J.T., 1998. Soil water balance and plant water stress. In: Tsuji, G.Y., Hoogenboom, G., Thornton, P.K. (Eds.), Understanding Options of Agricultural Production. International Consortium for Agricultural Systems Applications, Kluwer Academic Publishers, Dordrecht, The Netherlands, pp. 41-53.

Ritchie, J.T., Singh, U., Godwin, D.C., Bowen, W.T., 1998. Cereal growth, development and yield. In: Tsuji, G.Y., Hoogenboom, G., Thornton, P.K. (Eds.), Understanding Options of Agricultural Production. International Consortium for Agricultural Systems Applications, Kluwer Academic Publishers, Dordrecht, The Netherlands, pp. 79-98.

Seckler, D., 1996. The New Era of Water Resources Management: From Dry to Wet Water Savings. Research Report No. 1, International Water Management Institute, Colombo, Sri Lanka, 17 pp.

Seckler, D., Amarasinghe, U., Molden, D., de Silva, R., Barker, R., 1998. World Water Demand and Supply, 1990-2025: Scenarios and Issues. Research Report No. 19, International Water Management Institute, Colombo, Sri Lanka, 40 pp.

Tsuji, G.T., Uehara, G., Salas, S. (Eds.), 1994. DSSATv3.0, Vol. 3. University of Hawaii, Honolulu, Hawaii.

Van Dam, J.C., Huygen, J., Wesseling, J.G., Feddes, R.A., Kabat, P., van Waslum, P.E.V., Groenendjik, P., van Diepen, C.A., 1997. Theory of SWAP Version 2.0: Simulation of Water Flow and Plant Growth in the SoilWater-Atmosphere-Plant environment. Technical Document No. 45, DLO Winand Staring Center, Wageningen Agricultural University, The Netherlands.

Williams, J.R., 1995. The EPIC model. In: V. Singh (Ed.), Computer Models of Watershed Hydrology. Water Resources Publication, Highlands Ranch, CO, USA, pp. 910-999. 